\title{
Sistem Pendukung Keputusan Pemilihan Karyawan Terbaik pada PT. XYZ dengan Metode Profile Matching dan Interpolasi
}

\author{
Prayogi Perdana Nicolas ${ }^{\mathrm{a}}$, Hari Soetanto ${ }^{\mathrm{b} 2}$, Wahyudi ${ }^{\mathrm{a} 3}$, Ardiane Rossi ${ }^{\mathrm{a} 4}$ \\ ${ }^{a}$ Program Studi Magister Ilmu Komputer, Universitas Budi Luhur \\ Jl. Ciledug Raya, DKI Jakarta, 12260 \\ ${ }^{1}$ prayogi.nicolasegmail.com \\ ${ }^{2}$ hari.soetanto@budiluhur.ac.id \\ ${ }^{3}$ wahyudi.ubl18@gmail.com \\ ${ }^{4}$ ardianekurniawan@gmail.com
}

\begin{abstract}
Abstrak
Karyawan terbaik adalah tenaga kerja perusahaan yang memiliki kinerja terbaik diantara karyawan-karyawan lainnya. Salah satu upaya untuk meningkatkan kinerja karyawan dalam bekerja adalah dengan mengadakan kegiatan pemilihan karyawan terbaik. Masalah yang dihadapi PT. XYZ pada saat sebelum diadakannya penelitian ini adalah penilaian karyawan dilakukan dengan cara manual, yang tentu saja setiap penilai memiliki cara penilaian tersendiri dalam memilih karyawan terbaik. Hal ini menyebabkan proses pengambilan keputusan membutuhkan waktu yang lama dan hasilnya pun cenderung subjektif. Untuk menghilangkan masalah tersebut, diperlukan suatu sistem terkomputerisasi yang membantu pengambil keputusan dalam memilih karyawan terbaik, yaitu sistem pendukung keputusan (SPK) pemilihan karyawan terbaik pada PT. XYZ yang dibuat dengan menggunakan metode Profile Matching dan Interpolasi. Metode Profile Matching digunakan untuk pengambilan keputusan penilai, sedangkan metode Interpolasi digunakan untuk proses pembobotan tiap nilai, sehingga hasilnya akan menjadi objektif. Kriteria yang digunakan adalah Kualitas Kerja, Kuantitas Kerja, Disiplin, Inisiatif, Motivasi, Tanggung Jawab, Kerjasama, Adaptasi, Pemahaman Tugas, Pemecahan Masalah, Kepemimpinan, dan Pengambilan Keputusan. Setelah perhitungan nilai dilakukan dengan metode Profile Matching dan pembobotan dilakukan dengan metode Interpolasi, maka karyawan kode A099 (Dadap Hardiansyah) berhak menerima penghargaan karyawan terbaik dengan nilai tertinggi 3.875. Dengan demikian, SPK dengan menggunakan metode Profile Matching dan Interpolasi mampu merekomendasikan pemilihan karyawan terbaik dengan hasil perhitungan yang lebih cepat dan objektif, sehingga dapat digunakan sebagai pendukung keputusan pada PT. XYZ.
\end{abstract}

Kata kunci: Sistem Pendukung Keputusan (SPK), Karyawan Terbaik, Profile Matching, Interpolasi

\section{Best Employee Selection Decision Support System at PT. XYZ with Profile Matching and Interpolation Methods}

\begin{abstract}
The best employee is a company's workforce that has the best work performance among other employees. One way to increase the quality of employee is to hold the best employee award. The problem that faced PT. XYZ prior to this research is that the way the company evaluates the work performance is by manual method, which of course each evaluator has his own way in choosing the best employee. This causes the decision-making process takes a long time and the result tends to be subjective. To eliminate the problem, the company needs a computerized system that can help decision-maker in choosing the best employee. Thus, this research builds the best employee decision support system (DSS) by using by using Profile Matching and Interpolation methods. The Profile Matching method is for decision-making process, while Interpolation method is for weighting process so that the result will be more objective rather than subjective. There are 12 criteria in this research, which are Work Quality, Work Quantity, Discipline, Initiative, Motivation, Responsibility, Teamwork, Adaptation, Work Understanding, Problem Solving, Leadership, and Decision-Making. After the counting process is done by using Profile Matching method and the weighting process is done by using Interpolation method, the employee code A099 (Dadap Hardiansyah) deserves the best employee award with the highest score of 3.875. Hence, the DSS that uses Profile Matching and Interpolation methods is able to recommend the best employee selection with faster counting process and objective result, so it may be used as a decision-making tool at PT. XYZ.
\end{abstract}


Keywords: Decision Support System (DSS), Best Employee, Profile Matching, Interpolation

\section{Pendahuluan}

Pada era industri 4.0 seperti saat ini, peran teknologi sistem informasi sangatlah penting yang dimana teknologi sistem informasi sudah menjadi bagian dari kehidupan sehari-hari. Jika ingin bersaing dengan perusahaan lainnya, suatu perusahaan harus mengadaptasi penggunaan teknologi sistem informasi dalam kegiatan operasionalnya terutama untuk meningkatkan kualitas sumber daya manusia [1].

Salah satu bentuk upaya untuk meningkatkan mutu sumber daya manusia pada suatu perusahaan adalah dengan mengadakan penghargaan karyawan terbaik yang sekaligus mampu mengevaluasi kinerja karyawan. Penghargaan karyawan terbaik diberikan untuk menjaga motivasi karyawan supaya tetap berada pada tingkat yang tinggi yang secara tidak langsung membantu perusahaan berkembang lebih jauh. [2]. Menjaga motivasi karyawan tidaklah mudah, karena setiap karyawan memiliki masalahnya masing-masing yang berpotensi menyebabkan motivasi kerja menjadi rendah atau tinggi tergantung permasalahannya. Jika motivasi kerja seorang karyawan rendah, maka akan berdampak buruk pada kinerja karyawan tersebut [3].

Sistem pendukung keputusan (SPK) adalah salah satu produk teknologi sistem informasi yang dapat membantu pengambil keputusan untuk mengambil suatu keputusan apapun bentuk keputusannya. Namun, secanggih apapun teknologi yang digunakan, dibutuhkan sumber daya manusia yang kompeten untuk mengoperasikannya. Sumber daya manusia merupakan hal penting di dalam suatu perusahaan untuk mencapai visi dan misi perusahaan tersebut [4].

PT. XYZ adalah sebuah perusahaan yang bergerak di bidang manufaktur suku cadang otomotif. Sebelum penelitian ini dilakukan, PT. XYZ mengevaluasi kinerja karyawannya dengan menggunakan metode manual, dimana dalam proses pemilihannya membutuhkan waktu yang lama, tidak ada proses pembobotan, dan hasilnya pun cenderung subjektif.

Berdasarkan masalah tersebut, diperlukanlah suatu sistem pendukung keputusan yang mampu membantu pengambil keputusan dalam memilih karyawan terbaik pada PT. XYZ dengan menggunakan kriteria-kriteria yang telah ditentukan pihak manajemen perusahaan. Metode yang digunakan pada penelitian ini adalah Profile Matching dan Interpolasi.

\section{MetodologI}

\section{A. Sistem Pendukung Keputusan}

Sistem pendukung keputusan merupakan sebuah sistem yang membantu pengambil keputusan dalam menyelesaikan masalah yang semi-terstruktur [5], dengan menggunakan data yang telah dikumpulkan untuk kemudian diproses menjadi suatu informasi berupa rekomendasi suatu keputusan tertentu [6].

Pada dasarnya, SPK bertugas membantu pengambil keputusan dalam menentukan sebuah keputusan, yang artinya sistem tersebut harus sederhana, cepat dalam pemrosesan, dan juga mudah digunakan oleh pengambil keputusan. Atas dasar ini, SPK harus merupakan sistem yang berbasis komputer [7].

\section{B. Teknik Pengumpulan Data}

Teknik yang digunakan peneliti untuk mengumpulkan data adalah sebagai berikut:

1) Wawancara (interview): Peneliti melakukan wawancara kepada kepala departemen sumber daya manusia yang dilakukan dengan tatap muka dan tanya jawab melalui kuisoner.

2) Observasi (observation): Peneliti melakukan observasi secara langsung ke lapangan untuk mendapatkan informasi secara langsung tentang cara penilaian masing-masing kepala departemen.

3) Studi pustaka: Peneliti melakukan tinjauan pustaka dengan cara mengumpulkan beberapa referensi melalui berbagai macam sumber, seperti jurnal ilmiah, buku, ebook yang berhubungan tentang SPK dan metode Profile Matching dan Interpolasi.

\section{Metode Penelitian}

SPK pemilihan karyawan terbaik menggunakan dua metode, yaitu Profile Matching dan Interpolasi.

Metode Profile Matching adalah suatu metode yang membandingkan antara kompetensi individu dengan kompetensi ideal suatu jabatan sehingga dapat diketahui perbedaan kompetensinya [8]. Semakin kecil gap yang dihasilkan maka bobot nilai semakin besar, yang artinya seseorang memiliki peluang yang lebih besar untuk mendapatkan jabatan tersebut [9]. Ada beberapa tahapan dalam metode Profile Matching, yaitu [10]:

1) Mengidentifikasi kriteria dan nilai ideal masingmasing kriteria karyawan terbaik.

2) Mengelompokkan 12 kriteria menjadi core dan secondary factor, lalu besaran persentase tiap factor.

3) Identifikasi nilai aktual tiap karyawan: Nilai aktual tiap karyawan yang bersumber dari data milik HR Manager PT. XYZ.

4) Perhitungan nilai bobot dengan metode Interpolasi: Setelah data-data didapatkan, berikutnya adalah tahap perhitungan nilai bobot dengan metode Interpolasi untuk tiap karyawan. Gambarnya adalah sebagai berikut [11]:

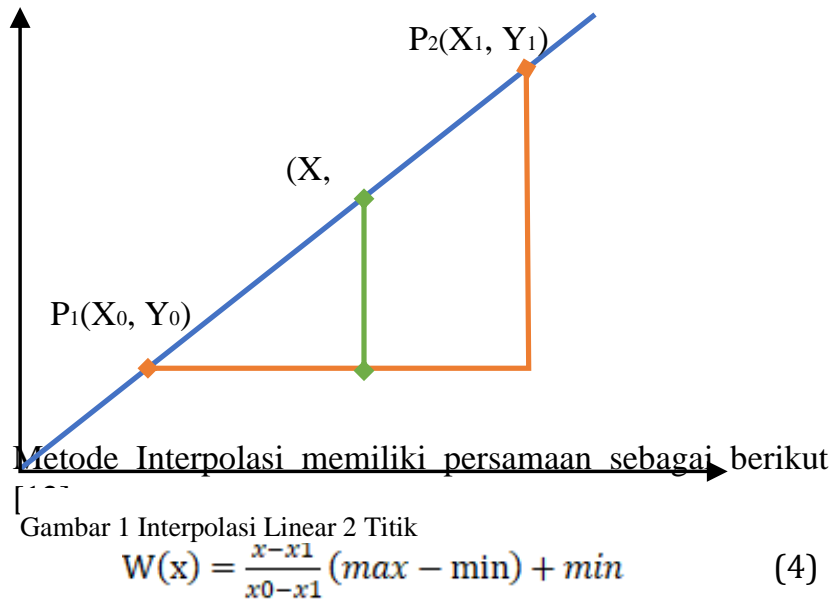


Keterangan:

$\mathrm{W}(\mathrm{x}) \quad$ : Nilai bobot untuk nilai input $\mathrm{x}$

$\mathrm{X} \quad$ : Nilai parameter

X0 : Kisaran nilai terkecil dari nilai parameter

$\mathrm{X} 1 \quad$ : Kisaran nilai terkecil dari nilai parameter

Max : Nilai penilaian tertinggi dari parameter penilaian tiap kriteria.

Min : Nilai penilaian terendah dari parameter

5) Perhitungan nilai core dan secondary factor tiap karyawan: Setelah pembobotan dengan Interpolasi selesai dilakukan, berikutnya adalah tahapan perhitungan nilai core dan secondary factor tiap karyawan. Aspek core factor adalah aspek yang paling dibutuhkan suatu jabatan yang mampu menghasilkan hasil yang optimal [13]. Perhitungannya adalah sebagai berikut [14]:

$$
\mathrm{NCF}=\frac{\Sigma N C}{\Sigma C}
$$

Keterangan:

$\mathrm{NCF}$ : Nilai rata-rata core factor

NC : Jumlah total nilai core factor

C : Jumlah item core factor

Sedangkan aspek secondary factor adalah aspek selain yang ada pada primary factor. Perhitungannya adalah sebagai berikut [14]:

$$
\mathrm{NSF}=\frac{\Sigma N S}{\Sigma S}
$$

Keterangan:

NSF : Nilai rata-rata secondary factor

NS : Jumlah total nilai secondary factor

$\mathrm{S} \quad$ : Jumlah item secondary factor

6) Nilai total: Setelah pengelompokan core dan secondary factor dilakukan, berikutnya adalah mencari nilai total core dan secondary factor yang rumusnya sebagai berikut [15]:

$$
\mathrm{Nt}=X \% N C F+X \% N S F
$$

Keterangan:

$\mathrm{Nt} \quad$ : Nilai total

NCF : Nilai rata-rata core factor

NSF : Nilai rata-rata secondary factor

$\mathrm{X} \% \quad$ : Nilai persentase yang diinput

Perankingan: Setelah total nilai aspek diketahui, maka tahapan terakhir adalah perankingan. Ranking didapatkan dengan mengurutkan nilai total tertinggi hingga terendah [16]. Karyawan ranking 1 dengan nilai total tertinggi memiliki arti karyawan tersebut memiliki kinerja terbaik sekaligus berhak menerima penghargaan karyawan terbaik.

\section{HASIL DAN PEMBAHASAN}

\section{A. Identifikasi Kriteria Dan Nilai Ideal Masing-Masing Kriteria Karyawan Terbaik}

Pada penelitian ini terdapat 12 kriteria karyawan terbaik dan nilai idealnya, sebagai berikut: penilaian tiap kriteria.

TABEL I

KRITERIA DAN NILAI IDEAL TIAP KRITERIA

\begin{tabular}{|l|l|}
\hline \multicolumn{1}{|c|}{ Kriteria } & Nilai Ideal \\
\hline Kualitas Kerja (S1) & 4 \\
\hline Kuantitas Kerja (S2) & 3 \\
\hline Disiplin (S3) & 3 \\
\hline Inisiatif (S4) & 3 \\
\hline Motivasi (S5) & 3 \\
\hline Tanggung Jawab (S6) & 3 \\
\hline Kerjasama (S7) & 4 \\
\hline Adaptasi (S8) & 3 \\
\hline Pemahaman Tugas (S9) & 3 \\
\hline Pemecahan Masalah (S10) & 3 \\
\hline Kepemimpinan (S11) & 4 \\
\hline Pengambilan Keputusan (S12) & 3 \\
\hline
\end{tabular}

B. Mengelompokkan 12 Kriteria Karyawan Terbaik Menjadi Core Dan Secondary Factor, Beserta Persentase Tiap Factor

Tahapan kedua adalah mengelompokkan 12 kriteria yang digunakan untuk memilih karyawan terbaik pada PT. XYZ ke core dan secondary factor. Berikut tabelnya:

TABEL II

KELOMPOK FAKTOR

\begin{tabular}{|ll|ll|}
\hline \multicolumn{2}{|c|}{ Core } & \multicolumn{2}{c|}{ Secondary } \\
\hline 1. & Kualitas Kerja (S1) & 1. & Kuantitas Kerja (S2) \\
2. & Disiplin (S3) & 2. & Tanggung Jawab (S6) \\
3. & Inisiatif (S4) & 3. & Kerjasama (S7) \\
4. & Motivasi (S5) & 4. & Adaptasi (S8) \\
5. & Pemahaman Tugas (S9) & 5. & Kepemimpinan (S11) \\
6. & Pemecahan Masalah (S10) & 6. & Pengambilan Keputusan (S12) \\
\hline
\end{tabular}

Kemudian besaran masing-masing core dan secondary factor juga harus ditentukan. Berikut tabelnya:

TABEL III

PERSENTASE FAKTOR

\begin{tabular}{|l|l|}
\hline Core & Secondary \\
\hline $75 \%$ & $25 \%$ \\
\hline
\end{tabular}

\section{Identifikasi Nilai Aktual Tiap Karyawan}

Berikut adalah nilai aktual tiap karyawan yang bersumber dari data milik HR Manager PT. XYZ:

TABEL IV

NILAI AKTUAL KARYAWAN KRITERIA S1-S6

\begin{tabular}{|l|l|l|l|l|l|l|}
\hline Kode & S1 & S2 & S3 & S4 & S5 & S6 \\
\hline A001 & 3 & 4 & 2 & 5 & 3 & 3 \\
\hline A002 & 3 & 4 & 5 & 1 & 2 & 3 \\
\hline A003 & 5 & 3 & 4 & 3 & 2 & 5 \\
\hline A004 & 3 & 4 & 1 & 2 & 2 & 1 \\
\hline A005 & 3 & 4 & 1 & 5 & 4 & 4 \\
\hline A006 & 3 & 5 & 5 & 2 & 2 & 3 \\
\hline A007 & 5 & 2 & 3 & 4 & 1 & 2 \\
\hline A008 & 4 & 3 & 3 & 1 & 1 & 1 \\
\hline A009 & 1 & 5 & 2 & 2 & 2 & 4 \\
\hline A010 & 2 & 2 & 2 & 1 & 4 & 5 \\
\hline---- & - & - & - & - & - & - \\
\hline A112 & 4 & 2 & 4 & 4 & 1 & 1 \\
\hline
\end{tabular}

TABEL V

NILAI AKTUAL KARYAWAN KRITERIA S7-S12

\begin{tabular}{|l|l|l|l|l|l|l|}
\hline Kode & S7 & S8 & S9 & S10 & S11 & S12 \\
\hline A001 & 3 & 3 & 1 & 4 & 5 & 5 \\
\hline A002 & 4 & 4 & 1 & 1 & 4 & 4 \\
\hline A003 & 5 & 3 & 1 & 4 & 1 & 3 \\
\hline A004 & 1 & 4 & 1 & 5 & 5 & 1 \\
\hline A005 & 3 & 4 & 3 & 5 & 2 & 3 \\
\hline
\end{tabular}




\begin{tabular}{|l|l|l|l|l|l|l|}
\hline A006 & 5 & 5 & 2 & 3 & 5 & 4 \\
\hline A007 & 2 & 1 & 3 & 4 & 3 & 1 \\
\hline A008 & 1 & 3 & 3 & 4 & 3 & 3 \\
\hline A009 & 1 & 4 & 3 & 3 & 2 & 2 \\
\hline A010 & 5 & 5 & 4 & 2 & 4 & 5 \\
\hline--- & - & - & - & - & - & - \\
\hline A112 & 2 & 1 & 2 & 3 & 1 & 1 \\
\hline
\end{tabular}

\section{Perhitungan Nilai Bobot Dengan Metode Interpolasi}

Setelah data nilai aktual tiap karyawan didapatkan, berikutnya adalah tahap perhitungan nilai bobot dengan menggunakan metode Interpolasi untuk tiap karyawan. Proses perhitungan nilai bobot dengan menggunakan metode Interpolasi dihitung dengan mengambil karyawan kode A001 sebagai contoh perhitungan sebagai berikut:

TABEL VI

NILAI BOBOT INTERPOLASI KARYAWAN A001

\begin{tabular}{|l|l|l|}
\hline $\begin{array}{l}\text { Karyawan } \\
\text { A001 }\end{array}$ & $\begin{array}{l}\text { Nilai } \\
\text { Aktual }\end{array}$ & Perhitungan \\
\hline Kualitas Kerja & 3 & $W(x)=\frac{3-5}{1-5}(5-1)+1=3$ \\
\hline $\begin{array}{l}\text { Kuantitas } \\
\text { Kerja }\end{array}$ & 4 & $W(x)=\frac{4-5}{1-5}(5-1)+1=2$ \\
\hline Disiplin & 2 & $W(x)=\frac{2-5}{1-5}(5-1)+1=4$ \\
\hline Inisiatif & 5 & $W(x)=\frac{5-5}{1-5}(5-1)+1=1$ \\
\hline Motivasi & 3 & $W(x)=\frac{3-5}{1-5}(5-1)+1=3$ \\
\hline $\begin{array}{l}\text { Tanggung } \\
\text { Jawab }\end{array}$ & 3 & $W(x)=\frac{3-5}{1-5}(5-1)+1=3$ \\
\hline $\begin{array}{l}\text { Kerjasama } \\
\text { Adaptasi }\end{array}$ & 3 & $W(x)=\frac{3-5}{1-5}(5-1)+1=3$ \\
\hline $\begin{array}{l}\text { Pemahaman } \\
\text { Tugas }\end{array}$ & 1 & $W(x)=\frac{3-5}{1-5}(5-1)+1=3$ \\
\hline $\begin{array}{l}\text { Pemecahan } \\
\text { Masalah }\end{array}$ & 4 & $w(x)=\frac{1-5}{1-5}(5-1)+1=5$ \\
\hline $\begin{array}{l}\text { Kepemimpinan } \\
\text { Pengambilan } \\
\text { Keputusan }\end{array}$ & 5 & $w(x)=\frac{4-5}{1-5}(5-1)+1=2$ \\
\hline
\end{tabular}

Dengan menggunakan proses perhitungan pada tabel VI diatas, didapatkan hasil sebagai berikut:

TABEL VII

NILAI BOBOT INTERPOLASI KRITERIA S1-S6

\begin{tabular}{|l|l|l|l|l|l|l|}
\hline Kode & S1 & S2 & S3 & S4 & S5 & S6 \\
\hline A001 & 3 & 2 & 4 & 1 & 3 & 3 \\
\hline A002 & 3 & 2 & 1 & 5 & 4 & 3 \\
\hline A003 & 1 & 3 & 2 & 3 & 4 & 1 \\
\hline A004 & 3 & 2 & 5 & 4 & 4 & 5 \\
\hline A005 & 3 & 2 & 5 & 1 & 2 & 2 \\
\hline A006 & 3 & 1 & 1 & 4 & 4 & 3 \\
\hline A007 & 1 & 4 & 3 & 2 & 5 & 4 \\
\hline A008 & 2 & 3 & 3 & 5 & 5 & 4 \\
\hline A009 & 5 & 1 & 4 & 4 & 4 & 2 \\
\hline A010 & 4 & 4 & 4 & 5 & 2 & 1 \\
\hline--- & - & - & - & - & - & - \\
\hline A112 & 2 & 4 & 2 & 2 & 5 & 5 \\
\hline
\end{tabular}

TABEL VII

NILAI BOBOT INTERPOLASI KRITERIA S7-S12

\begin{tabular}{|l|l|l|l|l|l|l|}
\hline Kode & S7 & S8 & S9 & S10 & S11 & S12 \\
\hline A001 & 3 & 3 & 5 & 2 & 1 & 1 \\
\hline A002 & 2 & 2 & 5 & 5 & 2 & 2 \\
\hline A003 & 1 & 3 & 5 & 2 & 5 & 3 \\
\hline A004 & 5 & 2 & 5 & 1 & 1 & 5 \\
\hline
\end{tabular}

\begin{tabular}{|l|l|l|l|l|l|l|}
\hline A005 & 3 & 2 & 3 & 1 & 4 & 3 \\
\hline A006 & 1 & 1 & 1 & 3 & 1 & 2 \\
\hline A007 & 4 & 5 & 3 & 2 & 3 & 5 \\
\hline A008 & 5 & 3 & 3 & 2 & 3 & 3 \\
\hline A009 & 5 & 2 & 3 & 3 & 4 & 4 \\
\hline A010 & 1 & 1 & 2 & 4 & 2 & 1 \\
\hline---- & - & - & - & - & - & - \\
\hline A112 & 4 & 5 & 4 & 3 & 5 & 5 \\
\hline
\end{tabular}

\section{E. Perhitungan Nilai Core Dan Secondary Factor Tiap} Karyawan

Tahapan berikutnya adalah mencari nilai core dan secondary factor. Contoh cara perhitungannya menggunakan karyawan A001 sebagai contoh, sebagai berikut:

TABEL VIII

CORE FACTOR DAN SECONDARY FACTOR KARYAWAN A001

\begin{tabular}{|l|l|l|l|}
\hline Core Factor & $\begin{array}{l}\text { Nilai Bobot } \\
\text { Interpolasi }\end{array}$ & $\begin{array}{l}\text { Secondary } \\
\text { Factor }\end{array}$ & $\begin{array}{l}\text { Nilai Bobot } \\
\text { Interpolasi }\end{array}$ \\
\hline $\begin{array}{l}\text { Kualitas Kerja } \\
\text { (S1) }\end{array}$ & 3 & $\begin{array}{l}\text { Kuantitas Kerja } \\
\text { (S2) }\end{array}$ & 2 \\
\hline Disiplin (S3) & 4 & $\begin{array}{l}\text { Tanggung Jawab } \\
\text { (S6) }\end{array}$ & 3 \\
\hline Inisiatif (S4) & 1 & Kerjasama (S7) & 3 \\
\hline Motivasi (S5) & 3 & Adaptasi (S8) & 3 \\
\hline $\begin{array}{l}\text { Pemahaman } \\
\text { Tugas (S9) }\end{array}$ & 5 & $\begin{array}{l}\text { Kepemimpinan } \\
\text { (S11) }\end{array}$ & 1 \\
\hline $\begin{array}{l}\text { Pemecahan } \\
\text { Masalah } \\
\text { (S10) }\end{array}$ & 2 & $\begin{array}{l}\text { Pengambilan } \\
\text { Keputusan (S12) }\end{array}$ & 1 \\
\hline
\end{tabular}

Berdasarkan pengelompokan core dan secondary factor pada tabel VIII, maka nilai core factor (NCF) karyawan A001 adalah sebagai berikut:

$$
\mathrm{NCF}=\frac{3+4+1+3+5+2}{6}=3
$$

Sedangkan nilai secondary factor (NSF) karyawan A001 adalah sebagai berikut:

$$
\mathrm{NSF}=\frac{2+3+3+3+1+1}{6}=2.167
$$

Dengan menggunakan persamaan yang digunakan untuk menghitung NCF dan NSF pada karyawan A001, maka didapatkan NCF dan NSF pada tiap karyawan, sebagai berikut:

TABEL VIII

$N C F$ DAN NSF TIAP KARYAWAN

\begin{tabular}{|l|l|l|}
\hline Kode & NCF & NSF \\
\hline A001 & 3 & 2.167 \\
\hline A002 & 3.833 & 2.167 \\
\hline A003 & 2.833 & 2.667 \\
\hline A004 & 3.667 & 3.333 \\
\hline A005 & 2.5 & 2.667 \\
\hline A006 & 3.167 & 1.5 \\
\hline A007 & 2.667 & 4.167 \\
\hline A008 & 3.333 & 3.5 \\
\hline A009 & 3.833 & 2 \\
\hline A010 & 3.5 & 1.667 \\
\hline--- & - & - \\
\hline A112 & 3 & 4.667 \\
\hline
\end{tabular}

\section{F. Perhitungan Nilai Total Tiap Karyawan}

Setelah NCF dan NSF tiap karyawan diketahui, maka tahapan berikutnya adalah mencari nilai total NCF dan 
NSF dengan menggunakan karyawan A001 sebagai contoh perhitungan, sebagai berikut:

$$
\begin{aligned}
& \mathrm{Nt}=0.75 * N C F+0.25 * N S F \\
& \mathrm{Nt}=(0.75 * 3)+(0.25 * 2.167) \\
& \mathrm{Nt}=2.792
\end{aligned}
$$

Dengan menggunakan cara perhitungan diatas, maka NCF dan NSF tiap karyawan adalah sebagai berikut:

TABEL IX

Nilai TOTAL TIAP KaRYAWAN

\begin{tabular}{|l|l|l|l|}
\hline Kode & NCF & NSF & Nt \\
\hline A001 & 3 & 2.167 & 2.792 \\
\hline A002 & 3.833 & 2.167 & 3.417 \\
\hline A003 & 2.833 & 2.667 & 2.792 \\
\hline A004 & 3.667 & 3.333 & 3.584 \\
\hline A005 & 2.5 & 2.667 & 2.542 \\
\hline A006 & 3.167 & 1.5 & 2.750 \\
\hline A007 & 2.667 & 4.167 & 3.042 \\
\hline A008 & 3.333 & 3.5 & 3.375 \\
\hline A009 & 3.833 & 2 & 3.375 \\
\hline A010 & 3.5 & 1.667 & 3.042 \\
\hline--- & - & - & - \\
\hline A112 & 3 & 4.667 & 3.417 \\
\hline
\end{tabular}

\section{G. Menentukan Ranking Karyawan Terbaik}

Setelah mengetahui nilai total tiap karyawan, maka tahapan terakhir adalah melakukan perankingan dengan cara mengurutkan nilai total terbesar hingga nilai total terkecil. Karyawan dengan nilai total terbesar adalah karyawan yang memiliki kinerja terbaik sekaligus berhak menerima penghargaan karyawan terbaik pada PT. XYZ. Berikut tabel rankingnya:

TABEL X

RANKING KARYAWAN

\begin{tabular}{|l|l|l|l|}
\hline Kode & Nama & Nilai Total & Ranking \\
\hline A099 & Dadap Hardiansyah & 3.875 & 1 \\
\hline A016 & Drajat G. Kurniawan & 3.833 & 2 \\
\hline A072 & Putu Pratama & 3.833 & 3 \\
\hline A043 & Tiara Kuswandari & 3.667 & 4 \\
\hline A066 & Aurora Mandasari & 3.667 & 5 \\
\hline A009 & Putri Suartini & 3.625 & 6 \\
\hline A015 & Nadia Winarsih & 3.625 & 7 \\
\hline A065 & Lidya Oktaviani & 3.583 & 8 \\
\hline A004 & Jindra Zulkarnain & 3.583 & 9 \\
\hline A085 & Tantri Handayani & 3.583 & 10 \\
\hline---- & ------ & ------ & --- \\
\hline A012 & Citra Utami & 1.458 & 112 \\
\hline
\end{tabular}

Jadi, berdasarkan tabel X setelah menggunakan metode Profile Matching dan Interpolasi, maka karyawan yang berhak menerima penghargaan karyawan terbaik pada PT. XYZ adalah karyawan A099 atas nama Dadap Hardiarnsyah, dengan nilai total 3.875.

\section{KESIMPULAN}

Tujuan dari penelitian ini adalah mengetahui siapa karyawan terbaik dengan 12 kriteria yang telah ditentukan perusahaan, yaitu Kualitas Kerja (S1), Kuantitas Kerja (S2), Disiplin (S3), Inisiatif (S4), Motivasi (S5), Tanggung Jawab (S6), Kerjasama (S7), Adaptasi (S8),
Pemahaman Tugas (S9), Pemecahan Masalah (S10), Kepemimpinan (S11), dan Pengambilan Keputusan (S12). Berdasarkan hasil perhitungan menggunakan metode profile matching dan interpolasi, didapatkan hasil bahwa karyawan A099 atas nama Dadap Hardiansyah mendapatkan nilai tertinggi, yaitu 3.875. Jadi karyawan tersebut berhak menerima penghargaan karyawan terbaik pada PT. XYZ. Dengan demikian, sistem pendukung keputusan (SPK) yang dibuat dengan menggunakan metode profile matching dan interpolasi dapat membantu pihak perusahaan dalam mengambil keputusan untuk menentukan karyawan terbaik pada PT. XYZ dengan hasil perhitungan yang lebih cepat dan hasilnya objektif sehingga dapat digunakan sebagai pendukung keputusan pada PT. XYZ.

\section{DAFTAR PUSTAKA}

[1] L. Rohida, "Pengaruh Era Revolusi Industri 4.0 terhadap Kompetensi Sumber Daya Manusia," J. Manaj. dan Bisnis Indones., vol. 6, no. 1, pp. 114-136, 2018, doi: 10.31843/jmbi.v6i1.187.

[2] I. M. A. B. Saputra and R. Wardoyo, "Group Decision Support System Determination Of Best Employee Using Topsis And Borda," IJCCS (Indonesian J. Comput. Cybern. Syst., vol. 11, no. 2, p. 165, 2017, doi: 10.22146/ijccs.22773.

[3] H. Simamora, Manajemen Sumber Daya Manusia (Edisi 3). CV. R.A. De. Rozarie, 2006

[4] E. Turban, J. E. Aronson, and T.-P. Liang, "Decision Support Systems and Intelligent Systems," Get. Res. Find. into Pract. Second Ed., p. 888, 2007, doi: 10.1002/9780470755891.ch11.

[5] A. A. Chamid and A. C. Murti, "Kombinasi Metode AHP dan TOPSIS Pada Sistem Pendukung Keputusan,” Snatif, pp. 115-119, 2017.

[6] A. Hafiz and M. Ma'mur, "Sistem Pendukung Keputusan Pemilihan Karyawan Terbaik Dengan Pendekatan Weighted Product," Cendikia, vol. 15, no. 2, pp. 23-28, 2018.

[7] M. Angeline, "Sistem Pendukung Keputusan Pemilihan Karyawan Terbaik Menggunakan Metode Profile Matching," STMB Multismart, vol. II, no. 2, pp. 45-51, 2018, [Online]. Available: http://www.stmbmultismart.ac.id/ejournal/index.php/JMBA/article/view/20.

[8] A. A. Tri Susilo, "Penerapan Metode Profile Matching Pada Sistem Pendukung Keputusan Pemilihan Ketua Program Studi (STUDI Kasus : Program Studi Teknik Informatika STMIK Musi Rawas)," JUITA J. Inform., vol. 5, no. 2, p. 87, 2018, doi: 10.30595/juita.v5i2.1939.

[9] M. Nashrullah Irfan, G. Abdillah, and F. Renaldi, "Sistem Pendukung Keputusan untuk Rekomendasi Promosi Jabatan ... (Nashrullah dkk.)," Sist. Pendukung Keputusan, vol. 5, no. 1, pp. 196-201, 2015.

[10] Y. Purwaningsih and R. Supriyanto, "Sistem Pendukung Keputusan Promosi Pejabat Struktural Melalui Diklat Kepemimpinan Iv Menggunakan Metode Profile Matching Studi Kasus Di Pppptk Bahasa Jakarta,” J. Apl. Bisnis dan Manaj., vol. 6, no. 1, pp. 74-85, 2020, doi: 10.17358/jabm.6.1.74.

[11] A. P. Godjali, "Sistem Pendukung Keputusan Penerimaan Karyawan Menggunakan Metode Profile Matching dengan Interpolasi dan TOPSIS Studi Kasus: PT. Inter Aneka Lestari Kimia (Aquaproof)," 2017.

[12] H. Soetanto, S. Hartati, R. Wardoyo, and S. Wibowo, "Hypertension drug suitability evaluation based on patient condition with improved profile matching," Indones. J. Electr. Eng. Comput. Sci., vol. 11, no. 2, pp. 453-461, 2018, doi: 10.11591/ijeecs.v11.i2.pp453-461.

[13] B. Sudrajat, "Pemilihan Pegawai Berprestasi Dengan Menggunakan Metode Profile Matching,” J. Inf. Syst. Applied, Manag. Account. Res., vol. 2, no. 4, pp. 20-28, 2018.

[14] I. F. Dwijaya, "Sistem Pendukung Keputusan Kenaikan Jabatan Pada PT. Sysmex Menggunakan Metode Profile Matching," STRING (Satuan Tulisan Ris. dan Inov. Teknol., vol. 2, no. 3, p. 282, 2018, doi: 10.30998/string.v2i3.2437. 
[15] S. Khoiriyah, Y. Yunita, and A. Junaidi, "Sistem Pendukung Keputusan Pemilihan Crew Store Terbaik Menggunakan Metode Profile Matching di PT. Sumber Alfaria Trijaya," J. Teknol. dan Ilmu Komput. Prima, vol. 2, no. 2, p. 27, 2019, doi: 10.34012/jutikomp.v2i2.668.

[16] Defiariany, "VOL . 9 NO . 1 April 2016," J. Teknol. Inf Pendidik., vol. 9, no. 1, pp. 153-162, 2016. 